J. Math. and Its Appl.

E-ISSN: 2579-8936

P-ISSN: $1829-605 \mathrm{X}$

Vol. 14, No. 2, Desember 2017, 103-112

\title{
Penerapan Min Plus Algebra Pada Penentuan Rute Tercepat Distribusi Susu
}

\author{
Vivi Suwanti ${ }^{1}$, Pohet Bintoto ${ }^{2}$, Riski Nur Istiqomah Dinullah ${ }^{3}$ \\ ${ }^{1}$ Universitas Kanjuruhan Malang, vivi_devbatghost@unikama.ac.id \\ ${ }^{2}$ Universitas Kanjuruhan Malang, pohet_bintoto@unikama.ac.id \\ ${ }^{3}$ Universitas Kanjuruhan Malang, ky2_zahra@unikama.ac.id
}

\begin{abstract}
Abstrak
Penelitian ini bertujuan untuk mencari rute tercepat yang bisa ditempuh untuk mendistribusikan susu dari produsen di daerah Kepanjen Malang ke Pabrik pengolah di daerah Tanggulangin dengan menggunakan algoritma Min Plus Algebra. Metode penelitian yang digunakan adalah kualitatif deskriptif. Tahap penelitian yang dilakukan meliputi 1) observasi lapangan, 2) pembuatan prototipe program Matlab Min plus algebra, 3) perhitungan rute tercepat menggunakan program Matlab, dan 4) analisis data. Dari hasil penelitian didapat digraf searah yang terdiri dari 10 titik sebagai representasi rute pengiriman. Dengan menggunakan prototipe program Matlab didapat jalur yang tercepat yang dapat dilalui adalah produsen - jalan Raya Kebon Agung - Gadang - jalur Arjosari - jalur jalan Raya Malang Pandaan lanjut tol - pabrik pengolah dengan waktu tempuh 134 menit.
\end{abstract}

Katakunci: min plus algebra, distribusi, tercepat

\section{PENDAHULUAN}

Distribusi susu merupakan salah satu aspek penting dalam rantai industri penghasil dan pengolah susu. Tingkat ketepatan waktu dalam perjalanan harus selalu diperhatikan untuk menjaga kualitas susu yang dikirimkan. Oleh karena itu dibutuhkan metode pencarian jalur terpendek untuk efisiensi proses perjalanan. 
Pada matematika, telah banyak ditemukan algoritma-algoritma untuk mencari jalur terpendek. Salah satunya adalah dengan menggunakan min plus algebra. Secara umum aljabar min-plus analog dengan aljabar maxplus, atau dapat dikatakan kedua struktur aljabarnya isomorfis. [1]

Definisi 1.1 Diberikan $R_{\varepsilon}:=R \cup\{\varepsilon\}$ dengan $R$ adalah himpunan semua bilangan real dan $\varepsilon:=\infty$. Pada $R_{\varepsilon}$ didefinisikan operasi berikut: $a \oplus b=\min (a, b)$ dan $a \otimes b=a+b$, untuk setiap $a, b \in R_{\varepsilon} \cdot[1]$

$R_{\varepsilon}$ adalah semiring idempotem komutatif dengan elemen identitas terhadap $\otimes$ adalah 0 dan elemen identitas terhadap $\oplus$ adalah $\varepsilon:=\infty$.

Definisi 1.2 Suatu jaringan lintasan searah $S$ adalah suatu graf berarah berbobot terhubung kuat taksiklik $S=(V, A)$, dengan $V=\{1,2, \ldots, n\}$ yang memenuhi kondisi: jika $(i, j) \in A$, maka $i<j$.[1]

Dalam jaringan lintasan searah ini, titik menyatakan persimpangan, arc/garis menyatakan suatu jalan, sedangkan bobot busur menyatakan jarak, sehingga bobot dalam jaringan selalu positif.

Teorema 1.1 Diberikan suatu jaringan lintasan searah dengan $n$ titik dan A adalah matriks bobot graf berarah dengan entri $a_{i j}=\left\{\begin{array}{c}\text { bobotarc, jika } i<j \text { dan titik } i \text { terhubung ke titik } j \\ \infty, \text { jika } i>j \text { atau titik } i \text { tidak terhubung ke titik } j\end{array}\right.$. Vektor saat-mulai paling awal titik $i$ dapat dilalui diberikan oleh $x^{e}=A^{*} \otimes b^{e}$ dimana $A^{*}=E \oplus A \oplus \cdots \oplus A^{n-1}$, dengan $E$ matriks berordo $n \times n$ dengan entri $e_{i j}=\left\{\begin{array}{c}0, \text { jika } i=j \\ \infty, \text { jika } i \neq j\end{array}\right.$ dan $b^{e}=\left[\begin{array}{llll}0 & \varepsilon & \cdots & \varepsilon\end{array}\right]^{T}$. Lebih lanjut $x_{n}^{e}$ merupakan waktu minimal untuk melintasi jaringan. [1]

Teorema 1.2 Diberikan suatu jaringan lintasan searah dengan $n$ titik dan A adalah matriks bobot graf berarah berbobot jaringan tersebut. Vektor saat-penyelesaian paling lambat titik diberikan oleh $x^{1}=-\left(\left(A^{*}\right)^{T} \otimes b^{1}\right)$ dimana $b^{1}=\left[\begin{array}{llll}\varepsilon & \varepsilon & \cdots & -x_{n}^{e}\end{array}\right]^{T}[1]$ 
Definisi 1.3 Suatu jalan $(i, j) \in A$ dalam jaringan lintasan searah $S$ disebut jalan terpendek jika $x_{i}^{e}=x_{i}^{1} \operatorname{dan} x_{j}^{e}=x_{j}^{1}[1]$

Berdasarkan [3], min plus algebra selalu benar secara matematis untuk perhitungan jarak terpendek serta mudah diterapkan baik secara manual maupun bahasa pemrograman. Pada penelitian ini, istilah jarak terpendek diganti dengan rute tercepat dengan pertimbangan bahwa pada praktik distribusi, jalan dengan jarak yang lebih pendek belum tentu dapat ditempuh dalam waktu yang lebih cepat. Adanya faktor kemacetan dapat memperlambat waktu tempuh suatu jalan. Hal ini disesuaikan pada pemodelan jaringan lintasan searah dimana bobot arc-nya diganti dengan waktu tempuh dari satu titik ke titik berikutnya. Oleh karena itu, penelitian ini bertujuan untuk menemukan rute tercepat pengiriman susu dengan menggunakan min plus algebra.

\section{METODE}

Penelitian ini merupakan penelitian yang bertujuan untuk menerapkan algoritma min plus algebra pada permasalahan rute terpendek/tercepat jalur distribusi susu. Oleh karena itu metode yang digunakan adalah metode penelitian kualitatif dengan jenis deskriptif.

Objek pada penelitian ini adalah salah satu penghasil susu segar di Malang yang melakukan pengiriman ke pabrik di area Tanggulangin. Data pada penelitian ini berupa 1) jenis kendaraan yang digunakan, 2) rute-rute yang bisa dilalui, 3) waktu tempuh tiap titik persimpangan.

Teknik pengumpulan data yang dilakukan pada penelitian ini meliputi (1) wawancara, (2) observasi lapangan, dan (3) dokumentasi. Langkah-langkah penelitian yang dilakukan adalah 1) studi literatur, 2) pengembangan prototipe program min plus algebra menggunakan Matlab, 3) pengambilan data lapangan pada salah satu produsen susu area Malang, dan 4) menerapkan prototipe program serta menganalisis hasil dengan kondisi praktik. 


\section{HASIL DAN PEMBAHASAN}

Berdasarkan hasil pengambilan data lapangan mengenai jalur pengiriman susu dari Kepanjen ke pabrik pengolah di Tanggulangin, didapatkan data sebagai berikut.

a. Pengiriman dilakukan dengan menggunakan mobil tangki sehingga mobil tidak melalui jalur tengah kota.

b. Waktu perjalanan telah ditambah dengan perkiraan tingkat kemacetan.

c. Untuk menuju Tanggulangin, satu-satunya jalur keluar truk dari Malang adalah melalui jalan raya Arjosari.

d. Berdasarkan wawancara yang dilakukan pada sopir truk tangki, waktu tempuh dalam praktik pengiriman susu dari Kepanjen ke pabrik adalah berkisar antara 2,5-3 jam dengan asumsi adanya kemacetan rutin pada jalur Malang Surabaya.

Rute yang dapat dilalui oleh mobil pengiriman susu dapat divisualisasikan dalam digraf berikut ini.

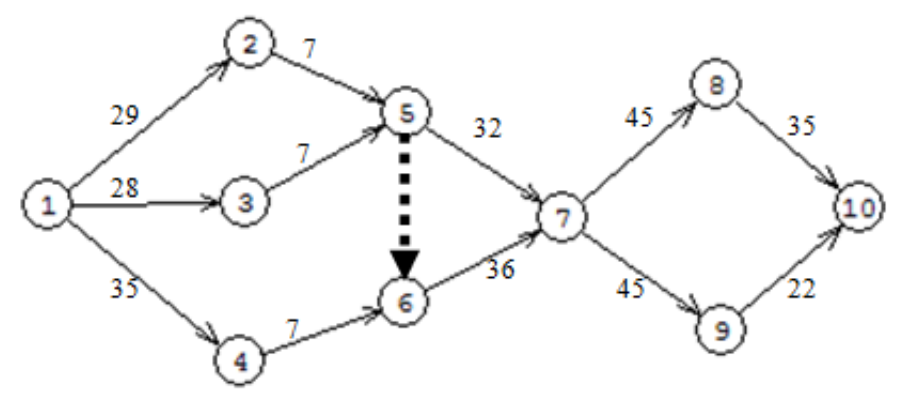

Gambar 1. Visualisasi digraf jalur truk

Keterangan:

1 : titik awal Produsen susu

2 : jalur jalan Raya Curung Rejo

3 : jalur jalan Raya Kebon Agung

4 : jalur jalan Raya Bululawang

5 dan 6 : area terminal Gadang

7 : jalur Arjosari

8 : jalur jalan Raya Malang-Pandaan dilanjutkan jalur non tol 
9 : jalur jalan Raya Malang-Pandaan dilanjutkan jalur tol Pandaan Surabaya

10 : titik akhir pabrik pengolah di Tanggulangin

Jarak pada digraf adalah waktu tempuh dari satu titik ke titik lain. Waktu tempuh dinyatakan dalam satuan menit. Untuk titik yang tidak terhubung maka entri matriks adalah $\varepsilon$ dimana $\varepsilon=\infty$. Bentuk matriks jarak telah disesuaikan dengan bentuk matriks pada [2] dan [1]. Representasi matriks jarak untuk graf pada gambar 1 adalah sebagai berikut ini.

$$
A=\left[\begin{array}{llllllllll}
\varepsilon & \varepsilon & \varepsilon & \varepsilon & \varepsilon & \varepsilon & \varepsilon & \varepsilon & \varepsilon & \varepsilon \\
29 & \varepsilon & \varepsilon & \varepsilon & \varepsilon & \varepsilon & \varepsilon & \varepsilon & \varepsilon & \varepsilon \\
28 & \varepsilon & \varepsilon & \varepsilon & \varepsilon & \varepsilon & \varepsilon & \varepsilon & \varepsilon & \varepsilon \\
35 & \varepsilon & \varepsilon & \varepsilon & \varepsilon & \varepsilon & \varepsilon & \varepsilon & \varepsilon & \varepsilon \\
\varepsilon & 7 & 7 & \varepsilon & \varepsilon & \varepsilon & \varepsilon & \varepsilon & \varepsilon & \varepsilon \\
\varepsilon & \varepsilon & \varepsilon & 7 & 0 & \varepsilon & \varepsilon & \varepsilon & \varepsilon & \varepsilon \\
\varepsilon & \varepsilon & \varepsilon & \varepsilon & 32 & 36 & \varepsilon & \varepsilon & \varepsilon & \varepsilon \\
\varepsilon & \varepsilon & \varepsilon & \varepsilon & \varepsilon & \varepsilon & 45 & \varepsilon & \varepsilon & \varepsilon \\
\varepsilon & \varepsilon & \varepsilon & \varepsilon & \varepsilon & \varepsilon & 45 & \varepsilon & \varepsilon & \varepsilon \\
\varepsilon & \varepsilon & \varepsilon & \varepsilon & \varepsilon & \varepsilon & \varepsilon & 35 & 22 & \varepsilon
\end{array}\right]
$$

Perhitungan min plus algebra dapat dilakukan dengan alur seperti pada algoritma berikut ini.

\section{Algoritma pencarian rute tercepat min plus algebra}

Input : matriks bobot $\mathrm{A}$

Output : saat mulai paling awal $x^{e}$, saat mulai paling lambat $x^{l}$

\section{Mulai}

Hitung $A^{*}=E \oplus A \oplus \cdots \oplus A^{n-1}$

Hitung $x^{e}=A^{*} \otimes b^{e}$

Hitung $b^{1}=\left[\begin{array}{llll}\varepsilon & \varepsilon & \cdots & -x_{n}^{e}\end{array}\right]^{T}$

Hitung $\left(A^{T}\right)^{*}=E \oplus A^{T} \oplus \cdots \oplus\left(A^{T}\right)^{n-1}$

Hitung $x^{1}=-\left(\left(A^{T}\right)^{*} \otimes b_{1}\right)$

Waktu tempuh $=0$; 
$\mathrm{p}=1$

For $\mathrm{i}=2$ to $\mathrm{n}$

if $x_{i}^{e}=x_{i}^{1}$ then

Hitung waktu tempuh $=$ waktu tempuh + waktu tempuh $(p, i) ;$

Masukkan titik $(p, i)$ dalam rangkaian rute

$\mathrm{p}=\mathrm{i}$

end;

end;

\section{Selesai}

Berdasarkan alur perhitungan pada algoritma, prototipe program min plus algebra dapat dibuat. Command program Matlab untuk min plus algebra adalah sebagai berikut.

\section{Program utama}

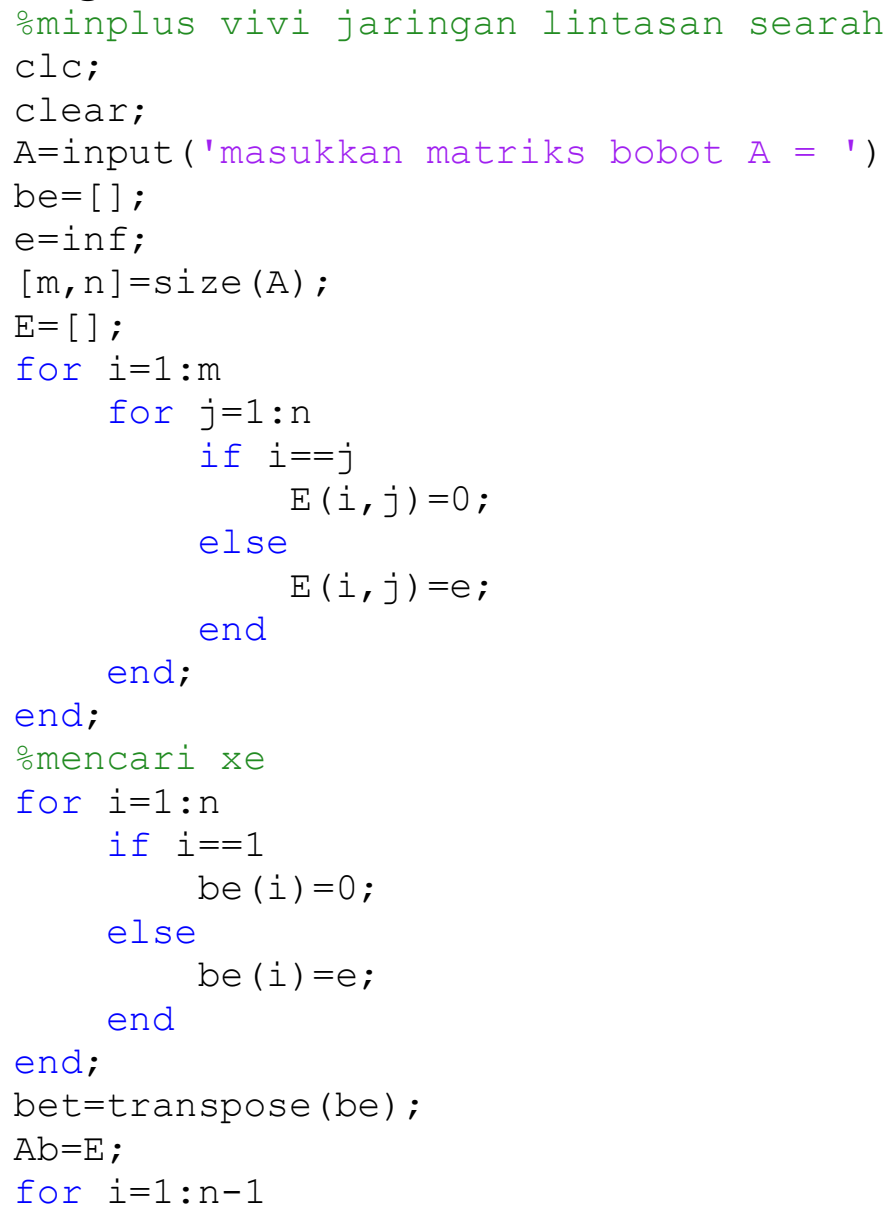




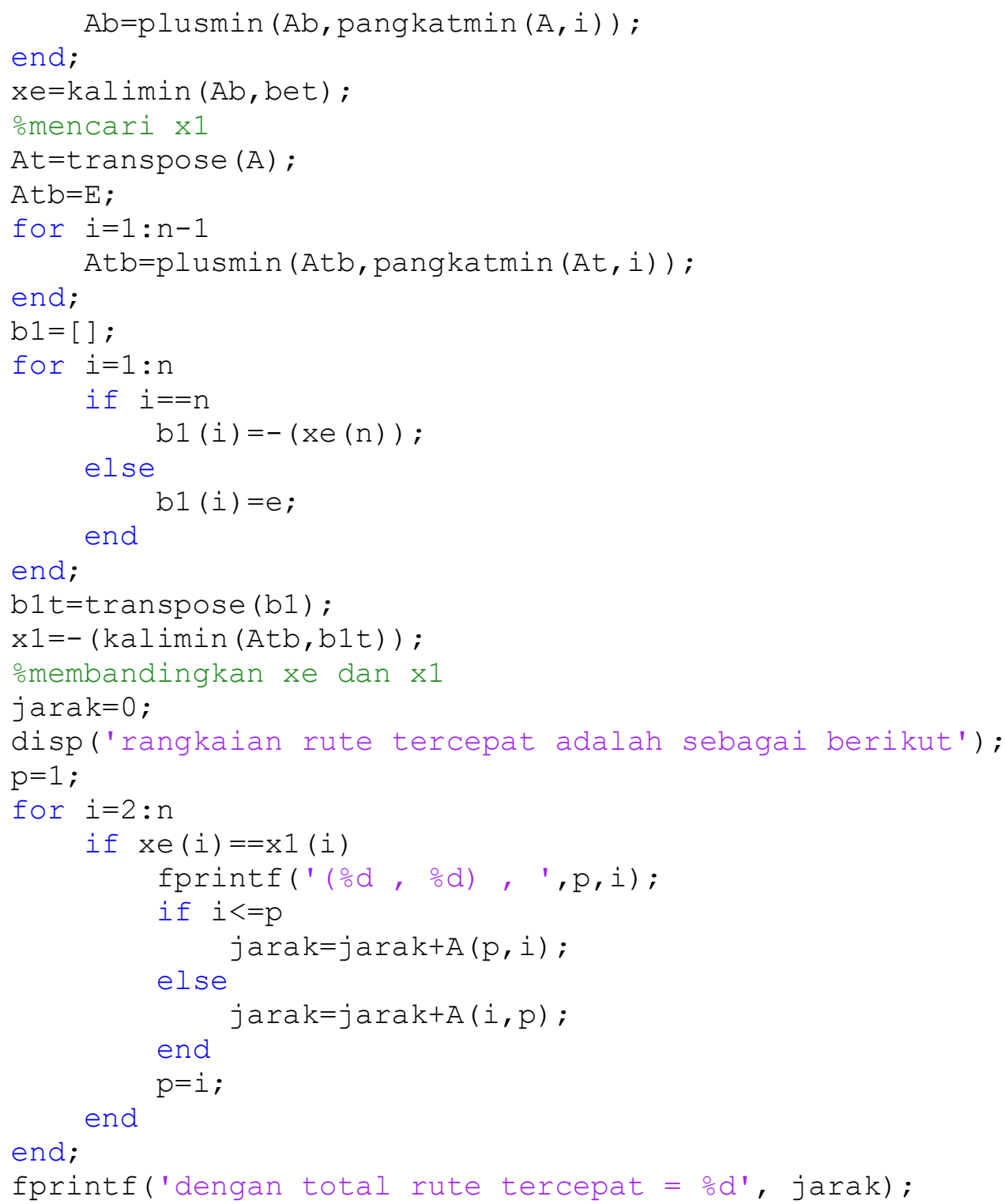

\section{Function transpose matriks}

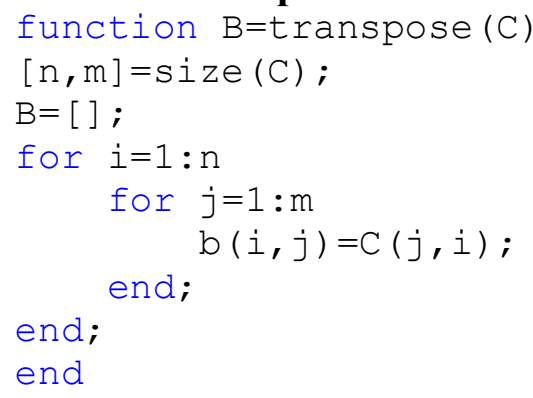

\section{Function penjumlahan matriks min plus algebra}

function $A m=p l u s m i n(A, B)$

if $\operatorname{size}(A)==\operatorname{size}(B)$

$[\mathrm{m}, \mathrm{n}]=\operatorname{size}(\mathrm{A})$; 


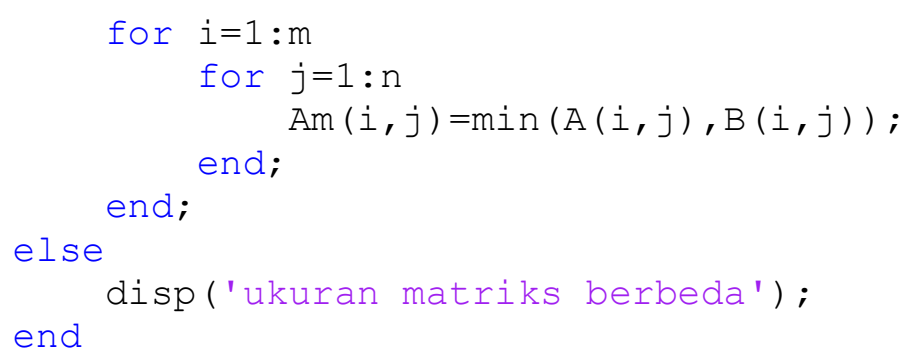

\section{Function perkalian matriks min plus algebra}

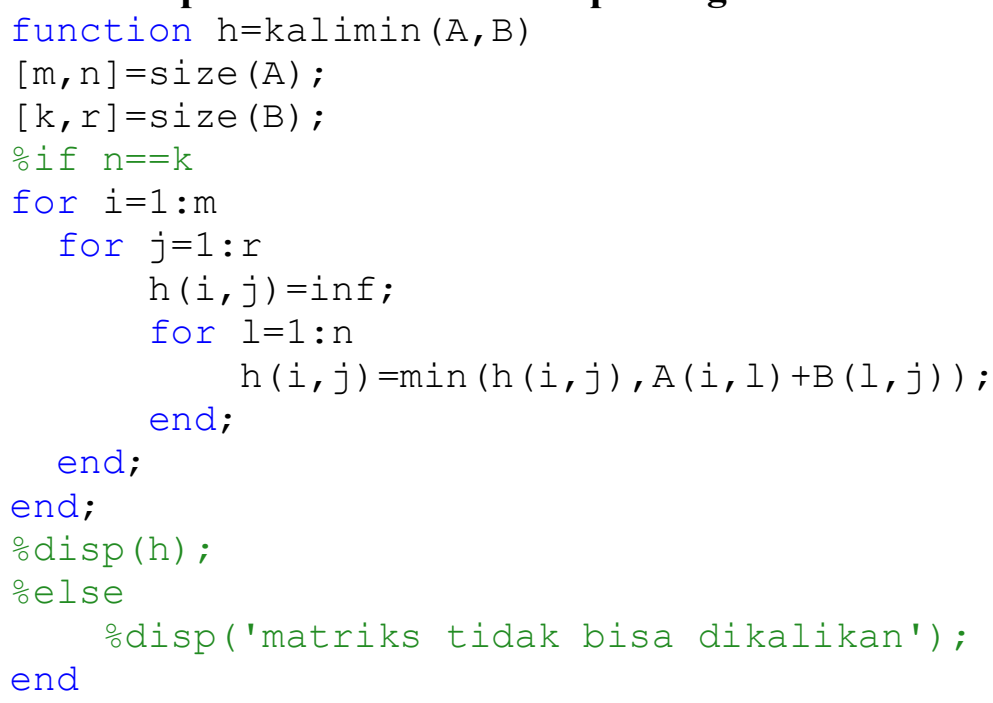

Function perpangkatan matriks min plus algebra

function $A p=$ pangkatmin $(A, n)$

$\mathrm{Ap}=\mathrm{A}$;

if $n==1$

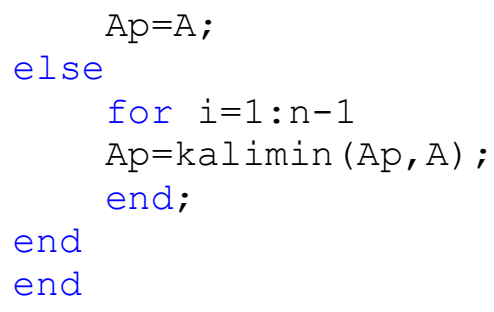

Hasil perhitungan rute tercepat dengan min plus algebra menggunakan program Matlab dapat dilihat pada gambar berikut. 


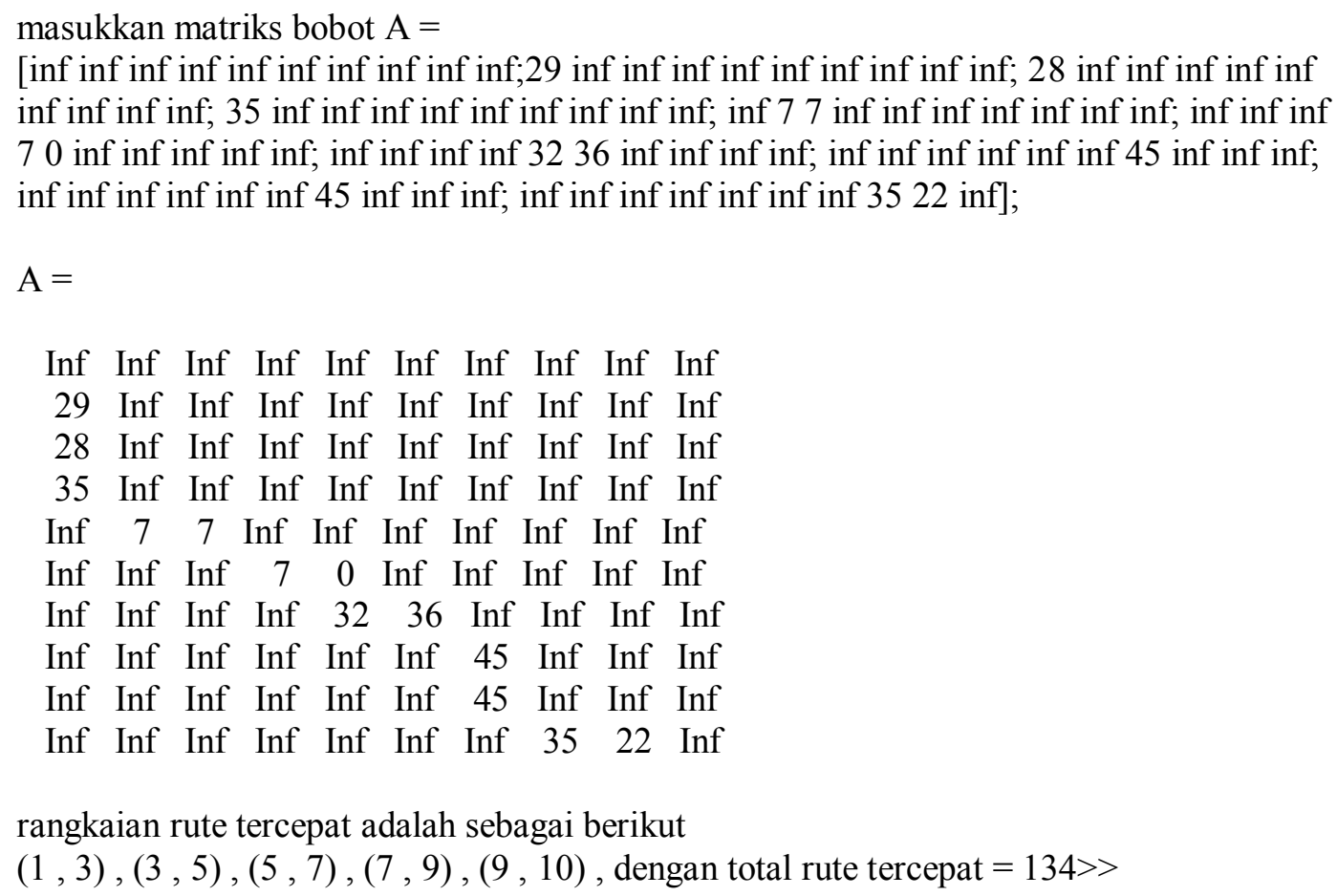

Gambar 2. Hasil perhitungan min plus algebra dengan program Matlab

Berdasarkan hasil perhitungan pada gambar 2 diketahui rute tercepat yang bisa dilalui adalah : $(1,3),(3,5),(5,7),(7,9),(9,10) \rightarrow$ produsen - jalan Raya Kebon Agung - terminal gadang - jalur arjosari jalur jalan Raya Malang Pandaan lanjut tol - pabrik di Tanggulangin. Total waktu yang diperlukan adalah 134 menit atau 2 jam 14 menit. Waktu yang tempuh hasil perhitungan ini merupakan hasil minimal sesuai dengan Suprayitno [3] yang menyatakan bahwa min plus algebra mampu menjamin bahwa prosedurnya selalu memberikan jawaban yang benar. Hal ini juga dibuktikan oleh Watanabe \& Watanabe [4] yang menyatakan bahwa ketunggalan nilai eigen pada matriks dengan input min plus algebra datang dari bobot rata-rata minimal dari sirkuit yang bersesuaian dengan matriks tersebut.

\section{Kesimpulan}

Penetapan jalur terpendek pada pengiriman dapat diperhitungkan dengan menggunakan min plus algebra. Panjang lintasan pada min plus algebra 
merupakan waktu tempuh dari satu titik ke titik berikutnya. Dengan menggunakan prototipe program Matlab didapat jalur yang tercepat yang dapat dilalui adalah produsen - jalan Raya Kebon Agung - terminal gadang - jalur arjosari - jalur jalan Raya Malang Pandaan lanjut tol - pabrik pengolah. Lama waktu yamg diperlukan adalah 134 menit atau 2 jam 14 menit. Untuk selanjutnya disarankan untuk melakukan penerapan min plus algebra pada masalah distribusi yang lebih kompleks dengan node yang lebih banyak. Selain itu, program yang dikembangkan dapat lebih diperbaiki lagi baik dalam segi codding maupun tampilan sehingga diperoleh program yang lebih mudah digunakan oleh umum.

\section{Pustaka}

[1] Rudhito, M. A., Aljabar Max Plus dan Penerapannya, Universitas Sanata Dharma, Yogyakarta, 2016.

[2] Subiono, Aljabar Min-Max Plus dan Terapannya, Jurusan Matematika-ITS, Surabaya, 2015

[3] Suprayitno, H., "Correctness Proof of Min-plus Algebra for Network Shortest-Paths Simultaneous Calculation" Journal of Technology and Social Science (JTSS), 1, 1, 61-69, 2017.

[4] Watanabe, S. \& Watanabe, Y., "Min Plus Algebra and Network" RIMS Kokyuroku Bessatsu, B47, 41-54, Research Institute for Mathematical Sciences, Kyoto University, 2014.

[5] Heidergott, B., Olsder, G.J., Woude, Jacob van der, Max Plus at Work: Modelling and Analisys of Synchronized Systems: A Course on MaxPlus Algebra and Its Application, Princeton University Press, New Jersey, 2006

[6] Schutter, B. D., Max-Algebraic System Theory for Discrete Event Systems, Thesis Ph.D., Katholieke Universiteit Leuven, Heverlee, 1996. 